\title{
Synbiotic supplementation in lean patients with non-alcoholic fatty liver disease: a pilot, randomised, double-blind, placebo-controlled, clinical trial
}

\author{
Fatemeh Mofidi ${ }^{1}$, Hossein Poustchi ${ }^{2}$, Zahra Yari $^{1}$, Babak Nourinayyer ${ }^{3}$, Shahin Merat $^{2}$, \\ Maryam Sharafkhah ${ }^{2,4}$, Reza Malekzadeh ${ }^{5}$ and Azita Hekmatdoost ${ }^{1,6_{*}}$ \\ ${ }^{1}$ Department of Clinical Nutrition and Dietetics, National Nutrition and Food Technology Research Institute, Faculty of \\ Nutrition and Food Technology, Shahid Beheshti University of Medical Science, Tehran 19816, Iran \\ ${ }^{2}$ Liver and Pancreatobiliary Diseases Research Group, Digestive Diseases Research Institute, Tehran University of Medical \\ Sciences, Tebran 14117, Iran \\ ${ }^{3}$ Mehrad Hospital, Tehran 15879, Iran \\ ${ }^{4}$ Department of Epidemiology and Biostatistics, Tehran University of Medical Sciences, Tebran 14117, Iran \\ ${ }^{5}$ Digestive Oncology Research Center, Digestive Diseases Research Institute, Tehran University of Medical Sciences, Tehran 14117, Iran \\ ${ }^{6}$ Division of Gastroenterology, Hepatology and Nutrition, British Columbia's Children's Hospital and Child and Family \\ Research Institute, University of British Columbia, Vancouver, BC, Canada V6H 3 V4
}

(Submitted 8 November 2016 - Final revision received 27 December 2016 - Accepted 6 January 2017-First published online 27 March 2017)

\section{Abstract}

Although non-alcoholic fatty liver disease (NAFLD) is the leading aetiology of liver disorders in the world, there is no proven treatment for NAFLD patients with normal or low BMI. The aim of this study was to evaluate the efficacy of synbiotics supplementation in NAFLD patients with normal or low BMI. In this randomised, double-blind, placebo-controlled, clinical trial, fifty patients with NAFLD were assigned to take either a synbiotic supplement or a placebo capsule for 28 weeks. Both groups were advised to follow a healthy lifestyle. At the end of the study, hepatic steatosis and fibrosis reduced in both groups; however, the mean reduction was significantly greater in the synbiotic group rather than in the placebo group $(P<0.001)$. Furthermore, serum levels of fasting blood sugar, TAG and most of the inflammatory mediators reduced in the synbiotic group significantly compared with the placebo group $(P<0 \cdot 05)$. Our results provide evidence that synbiotic supplementation improves the main features of NAFLD in patients with normal and low BMI, at least partially through reduction in inflammatory indices. Further studies are needed to address the exact mechanism of action of these effects.

Key words: Non-alcoholic fatty liver diseases: Fatty liver: Non-alcoholic steatohepatitis: Probiotics: Synbiotics: Prebiotics: Body weight

Non-alcoholic fatty liver disease (NAFLD) is the most common liver disorder worldwide ${ }^{(1)}$. The only proven treatment strategy for disease management is lifestyle modification and weight $\operatorname{loss}^{(2)}$, which is not applicable to patients with low or normal BMI. To our knowledge, there is no clinical trial on lean patients with NAFLD ${ }^{(3)}$.

Probiotics are live bacteria that provide beneficial effects by modulating the gut microbiota ${ }^{(4,5)}$, which results in reduction of pathogenic bacteria, enhancement of the gut barrier integrity, modulation of the immune system ${ }^{(4,6)}$ and finally inhibition of inflammation, especially in the liver because of its anatomical link to the intestine ${ }^{(4,6,7)}$. Prebiotics are fermentable foods that can induce specific changes in the composition and/or activity of the gastrointestinal microbiota and provide the optimal environment for growth and activity of probiotics ${ }^{(8)}$. Synbiotics are the combination of probiotics and prebiotics, which are more effective than probiotics or prebiotics alone in modulating the gut microbiota ${ }^{(9)}$.

Recently, we have shown that synbiotic supplementation plus lifestyle modification is significantly more effective than lifestyle modification alone in the treatment of NAFLD in overweight and obese patients ${ }^{(10)}$. On the other hand, Velayudham et al. ${ }^{(11)}$ have reported the beneficial effects of probiotics on hepatic fibrosis in a cholin-methionin-deficient model of NAFLD, which is a non-obese model of the disease. Thus, we hypothesised that synbiotic supplementation might be effective in the management of lean patients with NAFLD. To evaluate this hypothesis, we designed this randomised, double-blind, placebo-controlled, clinical trial, as well as to assess whether supplementation with synbiotics is effective in

Abbreviation: NAFLD, non-alcoholic fatty liver disease.

* Corresponding author: A. Hekmatdoost, email a_hekmat2000@yahoo.com 
treatment of lean patients with NAFLD, while addressing some mechanisms of its action.

\section{Methods}

The details of the study protocol have been explained previously $^{(12)}$. In brief, patients were identified and recruited from a referral centre for FibroScan examination (Echosense). The diagnosis of NAFLD was established according to the presence of steatosis with controlled attenuation parameter (CAP) score of $>263$, associated with elevated alanine aminotransferase (ALT) $>60 \mathrm{U} / 1$ for 6 months before the study and at the time of randomisation. Patients with NAFLD who were 18 years or older, with $\mathrm{BMI} \leq 25$, lack of history of alcohol consumption and no evidence of any other acute and chronic disorders of the liver (hepatitis B, C, etc.), biliary disease, autoimmune diseases, cancer and inherited disorders affecting the liver were included. Participants who took antibiotics, probiotic supplements and/or hepatotoxic medicines within 6 months before the start of the study and during the study, pregnant and breast-feeding women and those with $>10 \%$ of body weight loss during the study period were excluded from the study.

Participants were randomly allocated to receive either the synbiotic supplementation or the identical-appearing placebo capsules (maltodexterin) twice daily for 28 weeks. Each synbiotic capsule (Protexin; Probiotics International Ltd) contained 200 million bacteria of seven strains (Lactobacillus casei, Lactobacillus rhamnosus, Streptococcus thermophilus, Bifidobacterium breve, Lactobacillus acidophilus, Bifidobacterium longum and Lactobacillus bulgaricus) and prebiotic (125 mg fructo-oligosaccharide) and probiotic cultures (magnesium stearate (source: mineral and vegetable) and a vegetable capsule (hydroxypropylmethyl cellulose)). Adherence was assessed by capsule counts, confirmed at each visit. Both groups were advised to follow an energy-balanced diet and physical activity recommendations according to the Clinical Guidelines on the Identification, Evaluation and Treatment of Overweight and Obesity in Adults from the National Institutes of Health and the North American Association for the Study of Obesity ${ }^{(13)}$. Follow-up assessments were carried out every 7 weeks to assess participants' dietary intakes and compliance. Anthropometric measurements, FibroScan test, serum concentrations of liver enzymes, fasting blood sugar (FBS), insulin, lipid profiles, high-sensitive C-reactive protein (hs-CRP), TNF- $\alpha$ and the activity of NF- $\kappa \mathrm{B}$ in peripheral blood mononuclear cells (PBMC) were assessed at baseline and at the end of the study. NF- $\kappa \mathrm{B}$ p65 was assessed in PBMC nuclear extracts using ELISA kits (Cell Signaling) according to the manufacturer's protocol.

\section{Ethical issues and informed consent process}

The study protocol was approved by the ethics committee of National Nutrition and Food Technology Research Institute, Shahid Beheshti University of Medical Sciences (94-04-563). The investigators provided all related information at a level of complexity that was understandable to subjects. Before participation, a written informed consent form was signed and dated by the subject and investigator. The study protocol is registered on Clinicaltrial.gov with registration Identifier NCT02530138.

\section{Primary and secondary outcomes}

The primary outcome measure was a significant reduction in hepatic steatosis measured using CAP scores of the FibroScan test. Secondary outcome measures were hepatic fibrosis, hepatic enzymes, glycaemic indices, lipid profile concentrations of inflammatory factors in serum and PBMC, and anthropometric variables.

\section{Statistical analysis}

Data were analysed using SPSS software (version 16; SPSS). For all analyses, a $P$ value of 0.05 was considered statistically significant. Continuous and categorical data are presented as mean values and standard deviations and frequencies, respectively. Demographic variables were analysed using a $\chi^{2}$ or $t$ test, as appropriate. The data were analysed according to the intention-to-treat principle. In order to eliminate the effects of confounding factors, the ANCOVA test was used.

\section{Results \\ Characteristics of the patients}

A total of fifty patients, who met our inclusion criteria, were recruited for the present study and were randomly assigned to consume either synbiotic ( $n$ 25) or placebo capsules ( $n$ 25). The consort flow chart of the study is shown in Fig. 1 . The baseline clinical and demographic data of the participants were similar with respect to anthropometrics, biochemical and inflammatory characteristics as well as hepatic steatosis and fibrosis (Table 1).

\section{Primary outcome}

In all, $84 \%$ of patients completed 28 weeks of treatment. All enrolled patients were included in the analysis of outcomes. Hepatic steatosis reduced in both groups; however, the mean reduction in the synbiotic group was significantly greater compared with the placebo group $(P<0 \cdot 001)$ (Table 2$)$.

\section{Secondary outcomes}

Hepatic fibrosis decreased in both groups, but this reduction was significantly greater in the synbiotic group $(P<0.001)$ (Table 2). We found a significant decrease in hepatic enzymes within both groups; however, no significant differences were observed between the two groups except for aspartate aminotransferase (Table 3). At the end of the 28-week treatment period, significant improvements in lipid profile, FBS, homeostatic model assessment of insulin resistance (HOMA-IR) and quantitative insulin sensitivity check index (QUICKI) were observed; however, the differences between the two groups were significant only in the case of FBS and TAG, which were improved significantly by synbiotic rather than placebo 


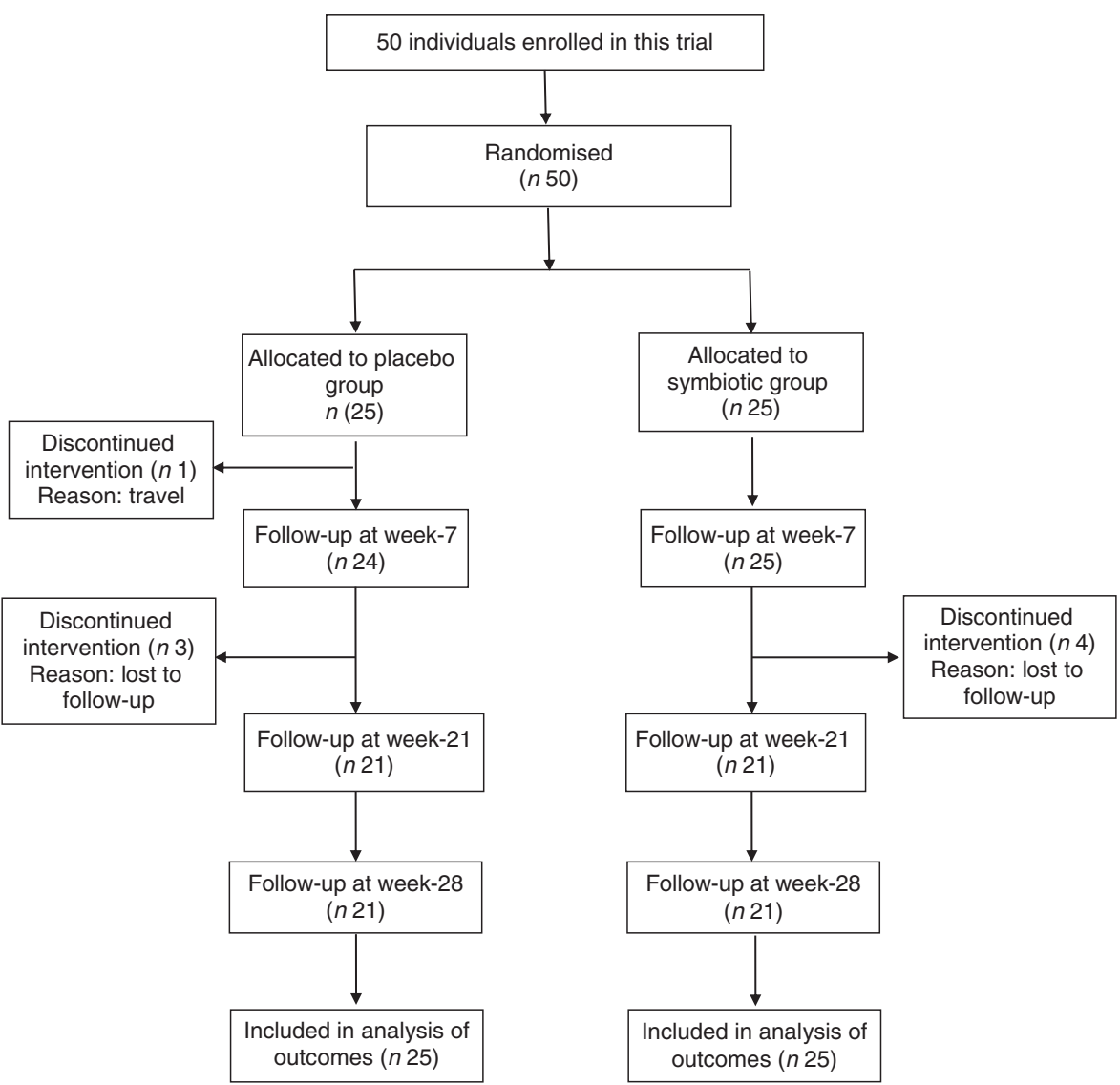

Fig. 1. Consolidated standards of reporting trials flow diagram of the study participants.

Table 1. Baseline characteristics at enrolment (Mean values and standard deviations)

\begin{tabular}{|c|c|c|c|c|c|c|c|}
\hline & \multicolumn{2}{|c|}{$\begin{array}{c}\text { Total } \\
(n 42)\end{array}$} & \multicolumn{2}{|c|}{$\begin{array}{l}\text { Synbiotic group } \\
\qquad(n 21)\end{array}$} & \multicolumn{2}{|c|}{$\begin{array}{l}\text { Placebo group } \\
\qquad(n 21)\end{array}$} & \multirow[b]{2}{*}{$P^{\star}$} \\
\hline & Mean & SD & Mean & SD & Mean & SD & \\
\hline Age (years) & $45 \cdot 35$ & $10 \cdot 69$ & 40.09 & 11.44 & 44.61 & $10 \cdot 12$ & 0.660 \\
\hline Sex (male/female) & \multicolumn{2}{|c|}{$23 / 19$} & \multicolumn{2}{|c|}{$11 / 10$} & \multicolumn{2}{|c|}{$12 / 9$} & 0.757 \\
\hline Smoking (yes/no) & \multicolumn{2}{|c|}{$5 / 37$} & \multicolumn{2}{|c|}{$3 / 18$} & \multicolumn{2}{|c|}{$2 / 19$} & 0.500 \\
\hline \multicolumn{8}{|l|}{ Metabolic characteristics } \\
\hline Height (cm) & 163.97 & 11.85 & $166 / 85$ & $12 \cdot 11$ & 161.09 & $11 \cdot 13$ & 0.112 \\
\hline Weight (kg) & $62 \cdot 72$ & $9 \cdot 81$ & 64.81 & $9 \cdot 44$ & $60 \cdot 64$ & $9 \cdot 95$ & 0.171 \\
\hline Waist circumference $(\mathrm{cm})$ & $90 \cdot 71$ & $5 \cdot 34$ & 92.00 & $4 \cdot 21$ & $89 \cdot 42$ & $6 \cdot 11$ & 0.122 \\
\hline BMI $\left(\mathrm{kg} / \mathrm{m}^{2}\right)$ & $23 \cdot 19$ & 1.03 & $23 \cdot 17$ & 1.01 & $23 \cdot 20$ & 1.07 & 0.925 \\
\hline Waist:hip ratio & 0.88 & 0.04 & 0.87 & 0.04 & 0.88 & 0.04 & 0.880 \\
\hline MET (h/d) & $32 \cdot 29$ & $4 \cdot 22$ & 32.43 & 3.77 & $32 \cdot 14$ & $4 \cdot 71$ & 0.829 \\
\hline Energy (kJ) & $8005 \cdot 87$ & 835.84 & $7846 \cdot 97$ & $595 \cdot 30$ & $8164 \cdot 74$ & $1012 \cdot 32$ & 0.226 \\
\hline Energy (kcal) & $1913 \cdot 45$ & $199 \cdot 77$ & $1875 \cdot 47$ & $142 \cdot 28$ & 1951.42 & 241.95 & 0.226 \\
\hline \multicolumn{8}{|l|}{ Serum biochemistry tests } \\
\hline ALT (IU/I) & $72 \cdot 81$ & 4.43 & $72 \cdot 29$ & $5 \cdot 08$ & 81.33 & $3 \cdot 73$ & 0.453 \\
\hline AST (IU/I) & $72 \cdot 12$ & $2 \cdot 73$ & 63.55 & 2.83 & $72 \cdot 70$ & 2.57 & 0.179 \\
\hline GGT (IU/I) & 81.45 & $10 \cdot 31$ & $83 \cdot 6$ & 11.53 & $76 \cdot 1$ & $8 \cdot 61$ & 0.790 \\
\hline \multicolumn{8}{|l|}{ Inflammatory factors } \\
\hline hs-CRP(ng/ml) & $2797 \cdot 47$ & $2076 \cdot 88$ & $2522 \cdot 33$ & $2119 \cdot 17$ & $3072 \cdot 61$ & $2047 \cdot 61$ & 0.397 \\
\hline TNF- $a(p g / m l)$ & $17 \cdot 86$ & $2 \cdot 81$ & $17 \cdot 66$ & 2.66 & 18.06 & 3.00 & 0.651 \\
\hline NF-кB p65 & 0.10 & 0.02 & 0.10 & 0.03 & 0.11 & 0.02 & 0.351 \\
\hline \multicolumn{8}{|l|}{ Liver histology } \\
\hline FibroScan (kPa) & $7 \cdot 45$ & 2.03 & 7.05 & $2 \cdot 34$ & $7 \cdot 86$ & 1.63 & 0.202 \\
\hline Steatosis & 309.97 & 36.65 & $336 \cdot 19$ & $30 \cdot 87$ & 300.67 & $18 \cdot 19$ & 0.065 \\
\hline
\end{tabular}

MET, metabolic equivalent of task; ALT, alanine aminotransferase; AST, aspartate aminotransferase; GGT, $\gamma$-glutamyl transpeptidase; hs-CRP, high-sensitive C-reactive protein * Based on ANCOVA model regressing change from baseline on treatment group and baseline value of the outcome. 
Table 2. Change from baseline to end of treatment in liver histology by treatment group

(Mean values with their standard errors)

\begin{tabular}{lrrrrrr}
\hline & \multicolumn{2}{l}{ Synbiotic group $(n$ 21) } & & \multicolumn{2}{l}{ Placebo group $(n$ 21) } \\
\cline { 2 - 3 } & Mean & SE & & Mean & SE & $P^{*}$ \\
\hline FibroScan $(\mathrm{kPa})$ & -1.71 & 0.25 & & -0.71 & 0.18 & $<0.001$ \\
Steatosis & -59.85 & 6.14 & & -14.14 & 1.04 & $<0.001$
\end{tabular}

* Based on ANCOVA model regressing change from baseline in the treatment group and baseline value of the outcome.

Table 3. Change from baseline to end of treatment in hepatic enzymes by treatment group

(Mean values with their standard errors)

\begin{tabular}{lllllll}
\hline & \multicolumn{2}{l}{ Synbiotic group $(n$ 21) } & & \multicolumn{2}{l}{ Placebo group $(n$ 21 $)$} & \\
\cline { 2 - 3 } \cline { 5 - 6 } & Mean & SE & & Mean & SE & $P^{*}$ \\
\hline ALT (IU/I) & -11.61 & 0.63 & & -5.04 & 0.13 & 0.061 \\
AST (IU/I) & -10.8 & 0.50 & & -1.98 & 0.09 & 0.005 \\
GGT (IU/I) & -28.65 & 1.88 & & -3.20 & 0.22 & 0.064 \\
\hline
\end{tabular}

ALT, alanine aminotransferase; AST, aspartate aminotransferase; GGT, $\gamma$-glutamy transpeptidase.

* Based on ANCOVA model regressing change from baseline in the treatment group baseline value of the outcome, and mean change of BMI, waist:hip ratio, WHR, metabolic equivalent of task and energy.

Table 4. Change from baseline to end of treatment in glycaemic and lipid profile by treatment group

(Mean values with their standard errors)

\begin{tabular}{|c|c|c|c|c|c|}
\hline & \multicolumn{2}{|c|}{$\begin{array}{l}\text { Synbiotic group } \\
(n 21)\end{array}$} & \multicolumn{2}{|c|}{$\begin{array}{l}\text { Placebo group } \\
\qquad(n 21)\end{array}$} & \multirow[b]{2}{*}{$P^{*}$} \\
\hline & Mean & SE & Mean & SE & \\
\hline $\mathrm{FBS}(\mathrm{mg} / \mathrm{dl}) \dagger$ & -17.33 & 4.98 & -2.47 & 0.52 & $<0.05$ \\
\hline Insulin $(\mathrm{mU} / \mathrm{l}) \dagger$ & 0.26 & 0.78 & -0.38 & 0.14 & 0.676 \\
\hline HOMA-IR & -0.10 & 0.22 & -1.32 & 0.03 & 0.881 \\
\hline QUICKI & 0.02 & 0.01 & 0.07 & 0.00 & 0.350 \\
\hline TAG $(\mathrm{mg} / \mathrm{dl}) \dagger$ & $-32 \cdot 23$ & 10.04 & -9.80 & $2 \cdot 35$ & $<0.001$ \\
\hline HDL-cholesterol (n & 3.69 & 1.64 & 0.95 & 0.75 & 0.736 \\
\hline LDL-cholesterol $(\mathrm{mg} / \mathrm{dl}) \dagger$ & -24.85 & 11.71 & -13.42 & $2 \cdot 39$ & 0.481 \\
\hline Total cholesterol $(\mathrm{mg} / \mathrm{dll}) \dagger$ & -46.09 & 12.04 & $-16 \cdot 00$ & 4.67 & 0.032 \\
\hline
\end{tabular}

FBS, fasting blood sugar; HOMA-IR, homeostatic model assessment of insulin resistance; QUICKI, quantitative insulin sensitivity check index.

* Based on ANCOVA model regressing change from baseline in the treatment group, and baseline value of the outcome.

† To convert FBS in $\mathrm{mg} / \mathrm{dl}$ to $\mathrm{mmol} / \mathrm{l}$, multiply by 0.0555 . To convert insulin in $\mathrm{mU} / \mathrm{l}$ to pmol/l, multiply by 6.945 . To convert TAG in $\mathrm{mg} / \mathrm{dl}$ to $\mathrm{mmo} / \mathrm{l}$, multiply by 0.0113 . To convert cholesterol in $\mathrm{mg} / \mathrm{dl}$ to $\mathrm{mmol} / \mathrm{l}$, multiply by 0.0259 .

Table 5. Change from baseline to end of treatment in inflammatory factors by treatment group

(Mean values with their standard errors)

\begin{tabular}{|c|c|c|c|c|c|}
\hline & \multicolumn{2}{|c|}{ Synbiotic group (n 21) } & \multicolumn{2}{|c|}{ Placebo group $(n 21)$} & \multirow[b]{2}{*}{$P^{*}$} \\
\hline & Mean & SE & Mean & SE & \\
\hline (ng/ml) & $-1162 \cdot 61$ & 437.65 & $-426 \cdot 57$ & $132 \cdot 41$ & $<0.05$ \\
\hline TNF- $a(\mathrm{pg} / \mathrm{ml})$ & $-1 \cdot 22$ & 0.82 & -0.30 & 0.22 & 0.229 \\
\hline NF-kB p65 & -0.01 & 0.00 & -0.01 & 0.00 & $<0.05$ \\
\hline
\end{tabular}

hs-CRP, high-sensitive C-reactive protein.

* Based on ANCOVA model regressing change from baseline in the treatment group, and baseline value of the outcome. supplementation (Table 4). All the inflammatory markers decreased after treatment in both groups, although the mean decrease in the synbiotic group was greater than that in the placebo group, except for TNF- $\alpha$ (Table 5). None of the patients completing the study had any serious adverse events, indicating tolerance to treatment. As shown in Table 6, none of the dietary components were significantly different between and within groups during the study period.

\section{Discussion}

To our knowledge, this is the first randomised, double-blind, placebo-controlled, clinical trial on lean NAFLD patients. Our results indicate that synbiotic supplementation improves hepatic features of NAFLD in patients with normal BMI.

The efficacy of synbiotic supplementation in NAFLD has been shown previously ${ }^{(10)}$. In our previous study, we found some evidence that synbiotic supplementation along with lifestyle modification is superior to lifestyle modification alone for the treatment of NAFLD in overweight and obese patients; however, lean patients were not included in that study. Although obesity is one of the main risk factors for fatty liver, it can also occur in lean subjects. Studies on liver donors and automobile crash victims have roughly found hepatic steatosis in $15 \%$ of non-obese subjects $^{(14,15)}$, which indicates that lean NAFLD might be a frequent cause of cryptogenic liver disorders. It seems that hepatic steatosis in lean people is a consequence of reduced $\beta$-oxidation of fatty acids, and decreased release of VLDL due to some genetic abnormalities $^{(16)}$. Although NAFLD is not rare in non-obese people $^{(3,17)}$, no proven treatment for lean NAFLD/non-alcoholic steatohepatitis (NASH) has been found yet.

Previous studies have shown that pathogenic bacteria products such as lipopolysaccharides (LPS) can move from the intestinal lumen to the lymphatic circulation. This activates the immune system, inducing regional and systemic inflammation, resulting in production of free radical species in the liver, which might contribute to development of NAFLD and $\mathrm{NASH}^{(18)}$. Thus, probiotics inhibit this procedure by reducing circulating LPS through modulation of intestinal microbiota, production of antibacterial substances and enhancement of gut barrier function results ${ }^{(19-21)}$. These beneficial effects of probiotics on NAFLD/NASH characteristics are due to reduction in oxidative stress and inflammation, whereas they are independent of metabolic disturbances involved in the pathogenesis of NAFLD/ $\mathrm{NASH}$ in obese people. Therefore, synbiotics can be an excellent therapeutic option for NAFLD patients with normal BMI.

In this study, the reduction in serum inflammatory cytokines was significantly greater in the synbiotic group except for TNF- $\alpha$, which is in line with the results of some previous studies. Li et al. ${ }^{(22)}$ reported that probiotics improved liver histology, reduced hepatic total fatty acid content and decreased serum ALT concentration. These effects were associated with a reduction in Jun N-terminal kinase (JNK), a TNF-regulated stress kinase that promotes hepatic insulin resistance, and $\mathrm{NF}-\kappa \mathrm{B}$ activity, fatty acid $\beta$-oxidation and mitochondrial uncoupling protein-2 expression, all markers and factors characterising insulin resistance; however, they did not observe a reduction 
Table 6. Changes from baseline in dietary intakes by treatment group (Mean values and $95 \%$ confidence intervals)

\begin{tabular}{|c|c|c|c|c|c|}
\hline & \multicolumn{2}{|c|}{ Synbiotic group ( $n$ 21) } & \multicolumn{2}{|c|}{ Placebo group ( $n$ 21) } & \multirow[b]{2}{*}{$P^{*}$} \\
\hline & Mean & $95 \% \mathrm{Cl}$ & Mean & $95 \% \mathrm{Cl}$ & \\
\hline \multicolumn{6}{|c|}{ Energy intake $(\mathrm{kJ} / \mathrm{d})$} \\
\hline Week 14 & 3.39 & $-205 \cdot 4,212 \cdot 1$ & 42.63 & $-150,2236$ & 0.312 \\
\hline Week 28 & -251.04 & $-1074 \cdot 0,571.9$ & $182 \cdot 88$ & $-5 \cdot 8,371.5$ & 0.174 \\
\hline \multicolumn{6}{|c|}{ Energy intake (kcal/d) } \\
\hline Week 14 & 0.81 & $-49 \cdot 1,50 \cdot 7$ & $10 \cdot 19$ & $-35 \cdot 9,56 \cdot 4$ & 0.312 \\
\hline Week 28 & $-60 \cdot 00$ & $-256 \cdot 7,136 \cdot 7$ & 43.71 & $-1 \cdot 4,88 \cdot 8$ & 0.174 \\
\hline \multicolumn{6}{|c|}{ Carbohydrate intake $(\mathrm{g} / \mathrm{d})$} \\
\hline Week 14 & -5.44 & $-26 \cdot 3,15$ & $5 \cdot 71$ & $-16 \cdot 5,27 \cdot 9$ & 0.138 \\
\hline Week 28 & $-12 \cdot 07$ & $-25 \cdot 2,1 \cdot 0$ & -4.37 & $-20 \cdot 7,12 \cdot 0$ & 0.073 \\
\hline \multicolumn{6}{|c|}{ Protein intake $(\mathrm{g} / \mathrm{d})$} \\
\hline Week 14 & 7.93 & $0 \cdot 3,15 \cdot 6$ & 3.06 & $-5 \cdot 9,12 \cdot 1$ & 0.643 \\
\hline Week 28 & 8.23 & $3 \cdot 2,13 \cdot 3$ & $6 \cdot 41$ & $-1 \cdot 6,14.4$ & 0.030 \\
\hline \multicolumn{6}{|c|}{ Fat intake $(g / d)$} \\
\hline Week 14 & -3.08 & $-11 \cdot 8,5 \cdot 6$ & $-2 \cdot 56$ & $-13 \cdot 6,8 \cdot 4$ & 0.372 \\
\hline Week 28 & 3.57 & $-1.8,8.9$ & 3.94 & $-3 \cdot 9,11 \cdot 8$ & 0.373 \\
\hline \multicolumn{6}{|c|}{ SFA intake $(\mathrm{g} / \mathrm{d})$} \\
\hline Week 14 & $2 \cdot 12$ & $-0.7,4.9$ & -1.29 & $-4 \cdot 6,2 \cdot 0$ & 0.338 \\
\hline Week 28 & 1.47 & $-1 \cdot 8,4 \cdot 8$ & 0.90 & $-1.9,3.7$ & 0.467 \\
\hline \multicolumn{6}{|c|}{$n-3$ Fatty acids intake $(\mathrm{g} / \mathrm{d})$} \\
\hline Week 14 & 0.01 & $-0.01,0.3$ & 0.42 & $-0.4,1.2$ & 0.288 \\
\hline Week 28 & 0.41 & $-0.1,1.0$ & 0.91 & $-0 \cdot 4,2 \cdot 2$ & 0.430 \\
\hline \multicolumn{6}{|c|}{ Cholesterol intake $(\mathrm{mg} / \mathrm{d})$} \\
\hline Week 14 & 1.67 & $-66 \cdot 1,69 \cdot 5$ & $-28 \cdot 42$ & $-82 \cdot 8,25 \cdot 9$ & 0.395 \\
\hline Week 28 & 56.65 & $-17 \cdot 4,130 \cdot 7$ & $-10 \cdot 37$ & $-69 \cdot 8,49 \cdot 0$ & 0.576 \\
\hline \multicolumn{6}{|c|}{ Fibre intake $(\mathrm{g} / \mathrm{d})$} \\
\hline Week 14 & 0.97 & $-2 \cdot 1,4 \cdot 1$ & 1.65 & $-1 \cdot 3,4 \cdot 6$ & 0.262 \\
\hline Week 28 & $1 \cdot 18$ & $-0.9,3.3$ & 1.65 & $-1 \cdot 2,4.5$ & 0.175 \\
\hline \multicolumn{6}{|c|}{ Vitamin C intake $(\mathrm{mg} / \mathrm{d})$} \\
\hline Week 14 & $8 \cdot 26$ & $-19 \cdot 8,36 \cdot 4$ & $30 \cdot 58$ & $5 \cdot 0,56 \cdot 2$ & 0.244 \\
\hline Week 28 & 1.80 & $-20 \cdot 0,23 \cdot 6$ & 59.46 & $-0.8,119 \cdot 7$ & 0.057 \\
\hline \multicolumn{6}{|c|}{ Vitamin E intake $(\mathrm{mg} / \mathrm{d})$} \\
\hline Week 14 & -1.63 & $-5 \cdot 7,2 \cdot 4$ & -0.58 & $-5 \cdot 3,4 \cdot 1$ & 0.370 \\
\hline Week 28 & 1.49 & $-1 \cdot 1,4 \cdot 1$ & $1 \cdot 14$ & $-3 \cdot 2,5 \cdot 5$ & 0.832 \\
\hline \multicolumn{6}{|c|}{ Vitamin A intake (IU) } \\
\hline Week 14 & 323.33 & $-143 \cdot 9,790 \cdot 6$ & $-41 \cdot 15$ & $-386 \cdot 9,304 \cdot 6$ & 0.206 \\
\hline Week 28 & 10.52 & $-204.45,225.5$ & $111 \cdot 14$ & $-322 \cdot 6,544 \cdot 9$ & 0.334 \\
\hline \multicolumn{6}{|c|}{ Carotenoids intake $(\mu \mathrm{g} / \mathrm{d})$} \\
\hline Week 14 & 445.49 & $-115 \cdot 4,1006 \cdot 4$ & 134.59 & $-353 \cdot 1,622 \cdot 2$ & 0.392 \\
\hline Week 28 & 280.09 & $-8 \cdot 7,568 \cdot 9$ & $310 \cdot 60$ & $-222 \cdot 3,843 \cdot 5$ & 0.755 \\
\hline \multicolumn{6}{|c|}{$\mathrm{Zn}$ intake $(\mathrm{mg} / \mathrm{d})$} \\
\hline Week 14 & 1.07 & $0.3,1.8$ & 0.80 & $-0.1,1.7$ & 0.758 \\
\hline Week 28 & 1.02 & $0.3,1.7$ & $1 \cdot 17$ & $0.4,1.9$ & 0.096 \\
\hline \multicolumn{6}{|c|}{ Se intake $(\mathrm{mg} / \mathrm{d})$} \\
\hline Week 14 & -0.001 & $-0.02,0.02$ & 0.001 & $-0.01,0.01$ & 0.460 \\
\hline Week 28 & 0.011 & $-0.01,0.03$ & 0.005 & $-0.004,0.01$ & 0.515 \\
\hline
\end{tabular}

* Based on ANCOVA model regressing change from baseline in the treatment group, and baseline value of the outcome.

in hepatic TNF- $\alpha$ gene expression. They suggested that as probiotics supplementation decreased hepatic activity of JNK, a TNF-regulated stress kinase that promotes hepatic insulin resistance, it is conceivable that probiotic therapy is able to modulate hepatic insulin sensitivity independent to its ability to regulate hepatic TNF- $\alpha$ gene expression. Furthermore, as NF- $\kappa \mathrm{B}$ was less activated in the synbiotic group than the placebo group, it seems that TNF- $\alpha$ gene expression was reduced by synbiotic consumption; however, its concentration in serum was not changed significantly.

The results of our previous study on overweight and obese patients with NAFLD showed a significant reduction in glycaemic indices as well as an improvement in serum lipid profile ${ }^{(10,23)}$, which were consistent with other studies on these patients $^{(21,24,25)}$. Synbiotics can improve insulin resistance through probable mechanisms such as modifying the gut flora, decreasing endotoxin concentrations, increasing faecal $\mathrm{pH}$ and reducing the production and absorption of intestinal toxins $^{(19,26)}$. Our results showed that synbiotic consumption could reduce only FBS and TAG significantly compared with placebo, and no significant difference was observed in other glycaemic indices and lipid profiles between the two groups. This discrepancy might be explained by the normal glycaemic indices and lipid profiles at baseline, and thus the reduction in these parameters was not significantly different between the two groups.

Another mechanism that might be involved in the beneficial effects of synbiotics consumption on NAFLD is the role of 
probiotics in modification of SCFA production by intestinal bacteria. Butyrate and propionate at low amounts exert multiple advantageous effects on the host, including the prevention of intestinal inflammation and oxidative stress, improvement of intestinal barrier function and stimulation of satiety and lipid oxidation in hepatocytes ${ }^{(27,28)}$. Acetate modulates insulin sensitivity and metabolic disorders ${ }^{(29)}$. SCFA have been identified as rich sources of energy for the host, and act as intestinotrophic agents to promote intestinal absorption of nutrients. Through their receptor G-protein-coupled receptor (GPR) 41 and GPR43, they reduce gut permeability and invasion of bacterial products via the portal vein and liver, and thus protect the liver from the ensuing damaging inflammation, which then results in down-regulation of insulin signalling in adipose tissue, thereby decreasing fat accumulation ${ }^{(30)}$.

One of the limitations of present study was that we could not obtain liver biopsies to evaluate the pathology score of the disease; however, we used transient elastography (FibroScan ${ }^{\circledR}$ ), which provides a quantitative, non-invasive evaluation of NAFLD by measuring hepatic steatosis (CAP score) and fibrosis ${ }^{(31,32)}$. It has been proven that this technique is a reliable, non-invasive method for identifying patients with significant hepatic steatosis and fibrosis. It is readily reproducible, and its score has low interand intra-observer variability ${ }^{(32)}$. Although there is another noninvasive fibrosis score system ${ }^{(33)}$, we could not use it because we did not measure all the parameters of this equation.

The most important advantage of the present study is that it is the first clinical trial on lean patients with NAFLD. Other strengths of this study are the relatively long duration of the study, evaluating NF- $\kappa$ B activity in PBMC, the stratified blocked randomisation design and the fact that all the patients of the study were newly diagnosed with NAFLD, not having received any previous treatment ${ }^{(34,35)}$.

In conclusion, this randomised, double-blind, placebocontrolled trial provides some evidence that synbiotic supplementation improves hepatic features of NAFLD in non-obese patients, at least partially through attenuation of inflammation. Whether these effects will sustain in longer treatment durations remains to be determined.

\section{Acknowledgements}

The authors are grateful to Protexin Company, UK, for their gift of synbiotic supplements.

This study was supported by a grant from the National Nutrition and Food Technology Research Institute of the Shahid Beheshti University and the Digestive Disease Research Center of the Shariati Hospital. Protexin Company, UK, provided the synbiotics supplements, and Nikan Teb Co. provided the FibroScan machine

F. M. and A. H. had full access to all the data of the study and took responsibility for the integrity of the data and the accuracy of data analysis. F. M., H. P., M. S., R. M. and A. H. conceived and designed the study and provided administrative support. F. M., H. P., Z. Y., B. N., S. M., R. M. and A. H. conducted the study. F. M. and A. H. wrote the manuscript.

The authors declare that there are no conflicts of interest.

\section{References}

1. Hashimoto E, Taniai M \& Tokushige K (2013) Characteristics and diagnosis of NAFLD/NASH. J Gastroenterol Hepatol 28, Suppl. 4, 64-70.

2. Ghaemi A, Taleban FA, Hekmatdoost A, et al. (2013) How much weight loss is effective on nonalcoholic fatty liver disease? Hepat Mon 13, e15227.

3. Vos B, Moreno C, Nagy N, et al. (2011) Lean non-alcoholic fatty liver disease (Lean-NAFLD): a major cause of cryptogenic liver disease. Acta Gastroenterol Belg 74, 389-394.

4. Eckburg PB, Bik EM, Bernstein CN, et al. (2005) Diversity of the human intestinal microbial flora. Science 308, 1635-1638.

5. Fanaro S, Chierici R, Guerrini P, et al. (2003) Intestinal microflora in early infancy: composition and development. Acta Paediatr Suppl 92, 48-55.

6. Mahowald MA, Rey FE, Seedorf H, et al. (2009) Characterizing a model human gut microbiota composed of members of its two dominant bacterial phyla. Proc Natl Acad Sci U S A 106, 5859-5864

7. McCarthy J, O'mahony L, O'callaghan L, et al. (2003) Double blind, placebo controlled trial of two probiotic strains in interleukin 10 knockout mice and mechanistic link with cytokine balance. Gut 52, 975-980.

8. Lim CC, Ferguson LR \& Tannock GW (2005) Dietary fibres as 'prebiotics': implications for colorectal cancer. Mol Nutr Food Res 49, 609-619.

9. Saulnier DM, Gibson GR \& Kolida S (2008) In vitro effects of selected synbiotics on the human faecal microbiota composition. FEMS Microbiol Ecol 66, 516-527.

10. Eslamparast T, Poustchi H, Zamani F, et al. (2014) Synbiotic supplementation in nonalcoholic fatty liver disease: a randomized, double-blind, placebo-controlled pilot study. Am J Clin Nutr 99, 535-542.

11. Velayudham A, Dolganiuc A, Ellis M, et al. (2009) VSL\# 3 probiotic treatment attenuates fibrosis without changes in steatohepatitis in a diet-induced nonalcoholic steatohepatitis model in mice. Hepatology 49, 989-997.

12. Mofidi F, Yari Z, Poustchi H, Merat S, et al. (2016) Effects of synbiotics supplementation in lean patients with nonalcoholic fatty liver disease: study protocol of a pilot randomized double-blind clinical trial. Arch Iran Med 19, 282-284.

13. National Heart, Lung, and Blood Institute Obesity Education Initiative, National Heart, Lung, and Blood Institute \& North American Association for the Study of Obesity (2002) The Practical Guide: Identification, Evaluation, and Treatment of Overweight and Obesity in Adults. San Antonio, TX: National Heart, Lung, and Blood Institute.

14. Fabbrini E, Sullivan S \& Klein S (2010) Obesity and nonalcoholic fatty liver disease: biochemical, metabolic, and clinical implications. Hepatology 51, 679-689.

15. Vernon G, Baranova A \& Younossi Z (2011) Systematic review: the epidemiology and natural history of non-alcoholic fatty liver disease and non-alcoholic steatohepatitis in adults. Aliment Pharmacol Ther 34, 274-285.

16. Nakatsuka A, Matsuyama M, Yamaguchi S, et al. (2016) Insufficiency of phosphatidylethanolamine N-methyltransferase is risk for lean non-alcoholic steatohepatitis. Sci $\operatorname{Rep}$ 6, 21721.

17. Margariti E, Deutsch M, Manolakopoulos S, et al. (2012) Nonalcoholic fatty liver disease may develop in individuals with normal body mass index. Ann Gastroenterol 25, 45-51.

18. Strieter R, Chensue S, Basha M, et al. (1990) Human alveolar macrophage gene expression of interleukin-8 by tumor necrosis factor-alpha, lipopolysaccharide, and interleukin1 beta. Am J Respir Cell Mol Biol 2, 321-326. 
19. Iacono A, Raso GM, Canani RB, et al. (2011) Probiotics as an emerging therapeutic strategy to treat NAFLD: focus on molecular and biochemical mechanisms. I Nutr Biochem 22 699-711.

20. Aller R, De Luis DA, Izaola O, et al. (2011) Effect of a probiotic on liver aminotransferases in nonalcoholic fatty liver disease patients: a double blind randomized clinical trial. Eur Rev Med Pharmacol Sci 15, 1090-1095.

21. Malaguarnera M, Vacante M, Antic T, et al. (2012) Bifidobacterium longum with fructo-oligosaccharides in patients with non alcoholic steatohepatitis. Dig Dis Sci 57, 545-553.

22. Li Z, Yang S, Lin H, et al. (2003) Probiotics and antibodies to TNF inhibit inflammatory activity and improve nonalcoholic fatty liver disease. Hepatology 37, 343-350.

23. Eslamparast T, Zamani F, Hekmatdoost A, et al. (2014) Effects of synbiotic supplementation on insulin resistance in subjects with the metabolic syndrome: a randomised, doubleblind, placebo-controlled pilot study. BrJ Nutr 112, 438-445.

24. Yadav H, Jain S \& Sinha PR (2007) Antidiabetic effect of probiotic dahi containing Lactobacillus acidopbilus and Lactobacillus casei in high fructose fed rats. Nutrition 23, 62-68.

25. Ma X, Hua J \& Li Z (2008) Probiotics improve high fat dietinduced hepatic steatosis and insulin resistance by increasing hepatic NKT cells. J Hepatol 49, 821-830.

26. Compare D, Coccoli P, Rocco A, et al. (2012) Gut-liver axis: the impact of gut microbiota on non alcoholic fatty liver disease. Nutr Metab Cardiovasc Dis 22, 471-476.
27. Hosseini E, Grootaert C, Verstraete W, et al. (2011) Propionate as a health-promoting microbial metabolite in the human gut. Nutr Rev 69, 245-258.

28. Hamer HM, Jonkers D, Venema K, et al. (2008) Review article: the role of butyrate on colonic function. Aliment Pharmacol Ther 27, 104-119.

29. van der Beek CM, Canfora EE, Lenaerta K, et al. (2016) Distal, not proximal, colonic acetate infusions promote fat oxidation and improve metabolic markers in overweight/obese men. Clin Sci (Lond) 130, 2073-2082.

30. Zhu L, Baker RD \& Baker SS (2015) Gut microbiome and nonalcoholic fatty liver diseases. Pediatr Res 77, 245-251.

31. Abenavoli L \& Beaugrand M (2012)) Transient elastography in non-alcoholic fatty liver disease. Ann Hepatol 11, 172-178.

32. Malekzadeh R \& Poustchi H (2011) Fibroscan for assessing liver fibrosis: an acceptable alternative for liver biopsy: Fibroscan: an acceptable alternative for liver biopsy. Hepat Mon 11, 157.

33. Angulo P, Hui JM, Marchesini G, et al. (2007) The NAFLD fibrosis score: a noninvasive system that identifies liver fibrosis in patients with NAFLD. Hepatology 45, 846-854.

34. Lindor KD, Kowdley KV, Heathcote EJ, et al. (2004) Ursodeoxycholic acid for treatment of nonalcoholic steatohepatitis: results of a randomized trial. Hepatology 39, 770-778.

35. Loguercio C, Federico A, Tuccillo C, et al. (2005) Beneficial effects of a probiotic VSL\#3 on parameters of liver dysfunction in chronic liver diseases. J Clin Gastroenterol 39, 540-543. 